\title{
Appearance of spiral patterns at the interference of spherical and vortex-bearing waves in the cases of torsion- and electric field- induced vortices in crystals
}

\author{
Vasylkiv Yu., Skab I. and Vlokh R. \\ Institute of Physical Optics, 23 Dragomanov St., 79005 Lviv, Ukraine, \\ vlokh@ifo.lviv.ua
}

Received: 07.03 .2012

\begin{abstract}
Basing on interference experiments, we have proved that both torsion of crystals around their three-fold symmetry axis and application of conically shaped electric field to crystals lead to the appearance of singly charged vortex beam. A spiral-like interference pattern has been observed in the conditions of torsion of $\mathrm{LiNbO}_{3}$ crystals and application of conically shaped electric field to $\mathrm{Bi}_{12} \mathrm{GeO}_{20}$ crystals.
\end{abstract}

Keywords: optical vortex, interference, torsion

PACS: $42.50 . \mathrm{Tx}, 78.20 . \mathrm{Jq}, 78.20 . \mathrm{hb}, 42.50 .-\mathrm{p}, 42.25 . \mathrm{Hz}$

UDC: $535.543,535.55,538.945 .5,548.1 .022$

In our recent works $[1,2]$ we have shown that torsion of crystals produces a singly charged vortex when a circularly polarized optical wave propagates along the torsion axis. This phenomenon can be observed in optically uniaxial crystals belonging to triginal system or in cubic crystals under torsion around three-fold symmetry axis [2]. We have also demonstrated [3-5] that the same singly charged vortex appears when a conically shaped electric field is applied to the crystals along their three-fold or six-fold inverse symmetry axes. The appearance of a doughnut mode in the both cases has been experimentally proved by detecting specific spatial distribution of optical indicatrix orientation around the vortex core (or the axis of twisting). Namely, the optical indicatrix is rotated by the angle $\zeta_{Z}=\varphi / 2$ whenever the tracing angle changes by $\varphi$. However, the commonly accepted proof for a helical mode is observation of spiral- or fork-like patterns in cases of its interference with spherical or plane waves, respectively. In the present work we will show that the spiral interference patterns do appear in the mentioned experiments, provided that the vortex-bearing mode is induced by torsion in $\mathrm{LiNbO}_{3}$ crystals or by electric field in $\mathrm{Bi}_{12} \mathrm{GeO}_{20}$ crystals.

A sample of $\mathrm{LiNbO}_{3}$ (the point symmetry group $3 \mathrm{~m}$ ) used in our experiments was prepared in the shape of octahedral prism, with its lateral faces parallel to $Z$ axis and the basis parallel to $X Y$ plane. The sample had the size of $13 \mathrm{~mm}$ along the optic axis $Z$ and the thickness of $6 \mathrm{~mm}$ between the lateral faces. The $Y Z$ plane was accepted to be parallel to one of the symmetry mirror planes. A light of He-Ne laser (the wavelength of $\lambda=632.8 \mathrm{~nm}$ ) propagated along the $Z$ axis. Torsion torques $M_{z}$ were applied to one of the base faces of the crystalline prism, while the opposite base face was kept fixed.

Cubic crystals of $\mathrm{Bi}_{12} \mathrm{GeO}_{20}$ represent a well-known electrooptic material, with the Pockels coefficient $r_{41}=3.5 \mathrm{pm} / \mathrm{V}$ and the refractive index $n=2.55$ for the wavelength $\lambda=632.8 \mathrm{~nm}$ [6]. The material possesses a notable optical activity effect (the specific optical rotation is equal to $\delta=20 \mathrm{deg} / \mathrm{mm}$ [6]). Besides, the above crystal is photorefractive and so can be used in optical 
storage devices (see, e.g., [7]). We prepared a crystalline plate perpendicular to the direction $<111>$, with the thickness of $6 \mathrm{~mm}$. A conically shaped electric field was applied along <111> direction and the light beam also propagated in this direction. The electric field was created using a wire-like electrode placed on the input face of a sample and a circle-shaped transparent electrode with the radius of $8 \mathrm{~mm}$, placed on the output face. The essential experimental details have been described elsewhere $[4,5]$.

Our interferometric experimental setup is shown in Fig. 1. We have used a Mach-Zehnder interferometer (see Fig. 1), in which the probing beam propagates through a right-handed circular polarizer 4 and a Z-cut of lithium niobate 6 (or a $<111>$ cut of $\mathrm{Bi}_{12} \mathrm{GeO}_{20}$ ), to which a torque moment (or a conically shaped electric field) is applied. The right-handed component of the incident light has been filtered with the aid of a left-handed circular polarizer 7. Then only a vortex-bearing beam is left behind the left-handed circular polarizer. A spherical wave propagates in the reference arm of our interferometer. The interference patterns have been detected with a CCD camera 10. As one can see from Fig. 2a, the interference patterns obtained for the case of zero twisting moment have a shape of almost circular closed curves. At the same time, the ring-like patterns are transformed into a single coil spiral when the moment $M_{Z}=0.098 \mathrm{~N} \times \mathrm{m}$ is applied (see Fig. 2b). The same behaviour is observed under application of conically shaped electric field to $\mathrm{Bi}_{12} \mathrm{GeO}_{20}$ crystals (see Fig. 3) These facts mean that both the torsion- and electrically-induced vortices reveal the same unit topological charge.

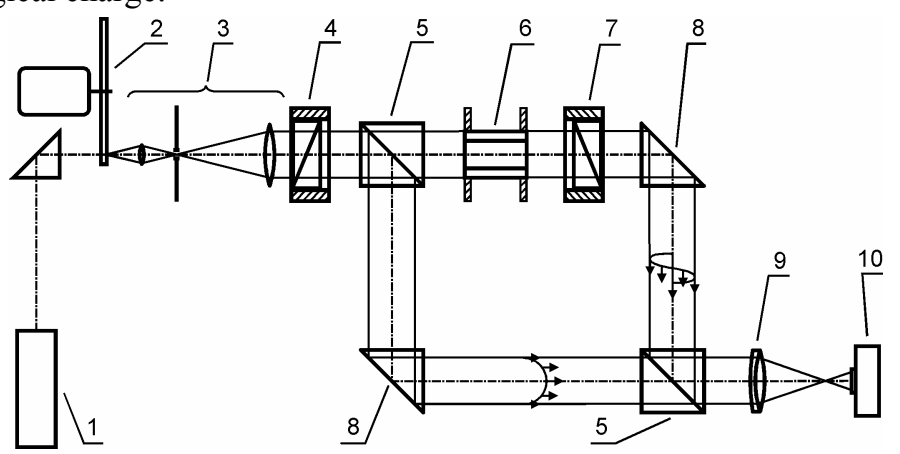

Fig. 1. Experimental set-up for studying the interference of helical and spherical waves: $1-\mathrm{He}-\mathrm{Ne}$ laser, $2-$ coherence scrambler, 3 - beam expander, 4 - right-handed circular polarizer, 5 - beam-splitting cubes, 6 - Zcut of lithium niobate crystal (or $<111>$ cut of $\mathrm{Bi}_{12} \mathrm{GeO}_{20}$ crystal), 7 - left-handed circular polarizer, 8 - mirrors, 9 - objective lens, 10 - CCD camera. The arrows indicate spherical and helical wave fronts in different arms of interferometer.
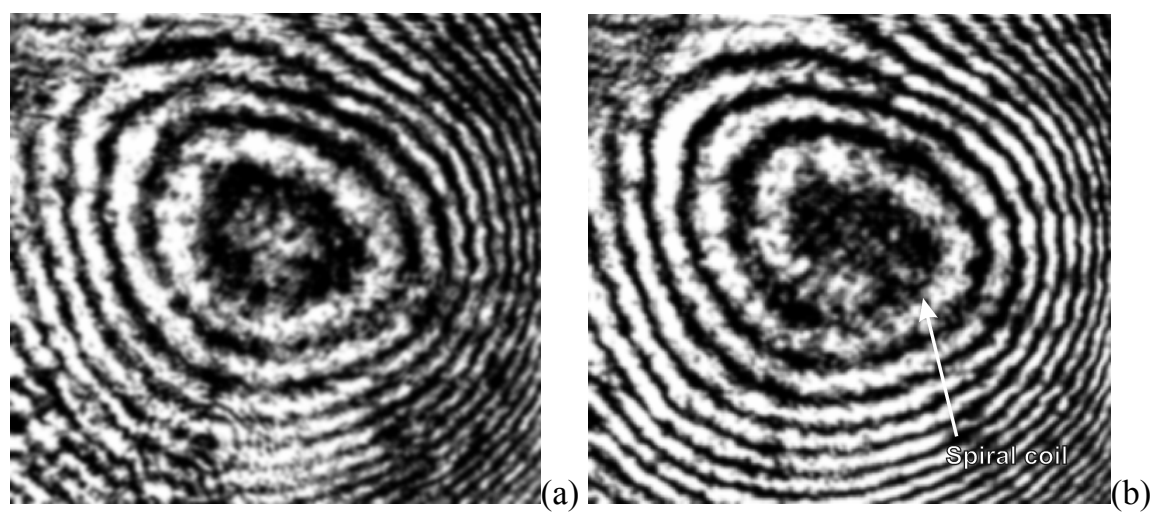

Fig. 2. Patterns observed due to interference of a spherical wave with a helical wave bearing optical vortex: (a) no torsion moment applied, and (b) the torsion moment $M_{z}=0.098 \mathrm{~N} \times \mathrm{m}$ is applied to $\mathrm{LiNbO}_{3} \mathrm{Crystals}_{\text {. }}$ 

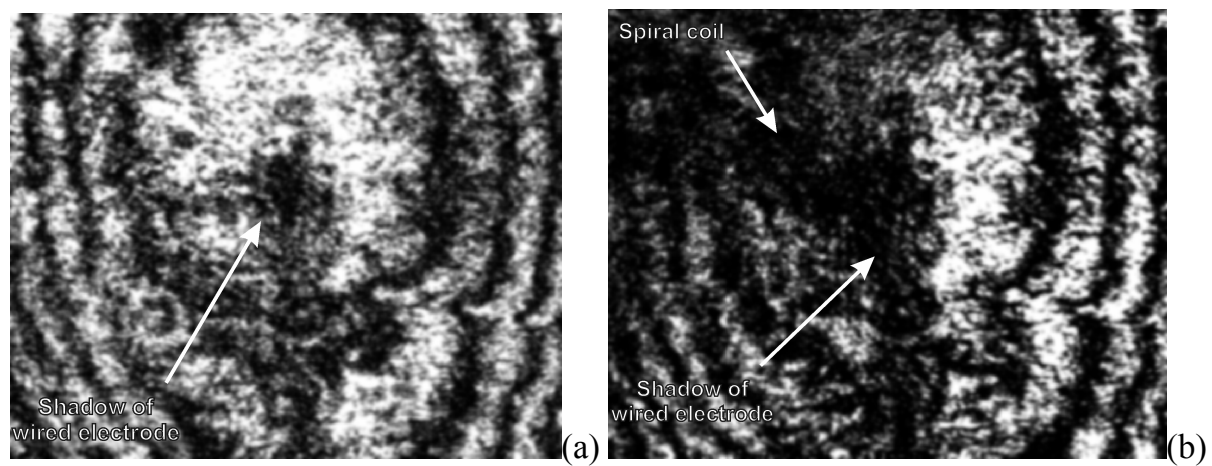

Fig. 3. Patterns observed due to interference of a spherical wave with a helical wave bearing optical vortex: (a) $\mathrm{np}$ conical electric field applied, (b) the conical electric field $E_{<111>}=6.0 \mathrm{kV}$ is applied to $\mathrm{Bi}_{12} \mathrm{GeO}_{20}$ crystals.

Hence, the results of our optical experiments described above prove, finally and unambiguously, the fact that both the torsion of crystals around the three-fold symmetry axis and the application of conically shaped electric field induce the singly charged vortex.

\section{References}

1. Skab I, Vasylkiv Y, Savaryn V and Vlokh R, 2011. Optical anisotropy induced by torsion stresses in $\mathrm{LiNbO}_{3}$ crystals: appearance of an optical vortex. J. Opt. Soc. Amer. A. 28: 633640.

2. Skab I, Vasylkiv Yu, Zapeka B, Savaryn V and Vlokh R, 2011. On the appearance of singularities of optical field under torsion of crystals containing three-fold symmetry axes. J. Opt. Soc. Amer. A. 28: 1331-1340.

3. Skab I P, Vasylkiv Yu V and Vlokh R O, 2011. On the possibility of electrooptic operation by orbital angular momentum of light beams via Pockels effect in crystals. Ukr. J. Phys. Opt. 12: 127-136.

4. Skab I, Vasylkiv Yu, Smaga I and Vlokh R, 2011. Spin-to-orbital momentum conversion via electrooptic Pockels effect in crystals. Phys. Rev. A. 84: 043815.

5. Vasylkiv Yu, Krupych O, Skab I and Vlokh R, 2011. On the spin-to-orbit momentum conversion operated by electric field in optically active $\mathrm{Bi}_{12} \mathrm{GeO}_{20}$ crystals Ukr. J. Phys. Opt. 12: $171-179$

6. http://www.almazoptics.com/BGO-BSO-BTO.html

7. Vogt H, Buse K, Hesse H and Kratzig E, 2001. Growth and holographic characterization of nonstoichiometric sillenite-type crystals. J. Appl. Phys. 90: 3167-3173.

Vasylkiv Yu., Skab I. and Vlokh R., 2012. Appearance of spiral patterns at the interference of spherical and vortex-bearing waves in the cases of torsion- and electric field-induced vortices in crystals. Ukr.J.Phys.Opt. 13: $50-53$.

Анотація. Використовуючи інтерференційний експеримент, ми остаточно довели, щэо кручення кристалів навколо осі симетрії третього порядку та прикладення конічного електричного поля приводять до появи променя, який містить оптичний вихор з одиничним зарядом. Спіральну інтерференційну картину спостерігали як результат скручування кристалів $\mathrm{LiNbO}_{3}$ і прикладання конічного електричного поля до кристалів $\mathrm{Bi}_{12} \mathrm{GeO}_{20}$. 